University of Louisville ThinkIR: The University of Louisville's Institutional Repository

Electronic Theses and Dissertations

$8-2017$

\title{
Gene expression of ammonium transporters in Ustilago maydis and their role in pathogenicity and virulence.
}

Kirsten Richardson

University of Louisville

Follow this and additional works at: https://ir.library.louisville.edu/etd

Part of the Life Sciences Commons

\section{Recommended Citation}

Richardson, Kirsten, "Gene expression of ammonium transporters in Ustilago maydis and their role in pathogenicity and virulence." (2017). Electronic Theses and Dissertations. Paper 2798.

https://doi.org/10.18297/etd/2798

This Master's Thesis is brought to you for free and open access by ThinkIR: The University of Louisville's Institutional Repository. It has been accepted for inclusion in Electronic Theses and Dissertations by an authorized administrator of ThinkIR: The University of Louisville's Institutional Repository. This title appears here courtesy of the author, who has retained all other copyrights. For more information, please contact thinkir@louisville.edu. 


\title{
GENE EXPRESION OF AMMONIUM TRANSPORTERS IN USTILAGO MAYDIS AND THEIR ROLE IN PATHOGENICITY AND VIRULENCE
}

\author{
By \\ Kirsten Richardson \\ B.A. Keuka College, 2015

\begin{abstract}
A Thesis
Submitted to the Faculty of the College of Arts and Sciences of the University of Louisville

In Partial Fulfillment of the Requirements for the Degree of
\end{abstract}

Masters of Science in Biology

Department of Biology

University of Louisville

Louisville, KY

August, 2017 
Copyright 2017 by Kirsten Richardson

All Rights Reserved 

GENE EXPRESION OF AMMONIUM TRANSPORTERS IN USTILAGO MAYDIS AND THEIR ROLE IN PATHOGENICITY AND VIRULENCE

\author{
By
}

Kirsten Richardson

Keuka College, 2015

A Thesis Approved on

August 1 $1^{\text {st }}, 2017$

By the following Thesis Committee:

Thesis Director

Dr. Michael Perlin

Dr. Carolyn Klinge

Dr. Mark Running 


\section{ACKNOWLEDGMENTS}

I would like to thank my PI, Dr. Michael Perlin, for accepting me into the Goat Lab and guiding me through my coursework and research over the past two years. It takes a truly special person to not only lead by example but to also create an awesome laboratory atmosphere to work in. I would also like to thank Dr. Carolyn Klinge for introducing me to the world outside of New York at the University of Louisville when she so graciously accepted me into her lab for a summer research project in 2014 and accepted a spot on my committee. Thank you to Dr. Mark Running for not only agreeing to serve on my committee but also for the helpful suggestions along the way. A huge thank you to the soon to be $D r$. Margaret Wallen for her guidance throughout my entire masters career and a lasting friendship. Last, but not least, thank you to the rest of the Goat Lab members, especially Hector Mendoza and Madison Furnish, for their help and dedication in my project. I am very fortunate for the relationships I have built while at the University of Louisville, making this experience much easier and more enjoyable. 


\title{
ABSTRACT \\ GENE EXPRESION OF AMMONIUM TRANSPORTERS IN USTILAGO MAYDIS AND THEIR ROLE IN PATHOGENICITY AND VIRULENCE
}

\author{
Kirsten Richardson
}

August 1 $1^{\text {st }}, 2017$

The fungus, Ustilago maydis, a plant pathogen of Zea mays, is capable of a dimorphic switch, e.g., a transition between a yeast-like form and a filamentous form. This switch is activated when $U$. maydis cells are starved for their preferred nitrogen source - ammonium. U. maydis has two important genes that play a role in this switch, umpl and ump2. Each gene is responsible for the uptake of ammonium and the latter is responsible for the filamentous response in the absence of ammonium. Ump2 deletion mutants are unable to filament in response to low ammonium while umpl deletion mutants do not show this phenotype. The Ump2 protein is responsible, not only for ammonium transport, by also for sensing the ammonium in the environment around the cell; in contrast, umpl is solely a low-affinity, high-capacity transporter of ammonium and is not required for the filamentous response. Unexpectedly, single deletion strains and double deletion strains (i.e., $\Delta u m p 1 \Delta u m p 2)$ are still able to grow in low ammonium conditions.

The present study investigates the roles of ploidy (haploid vs. diploid strains), promoter type (native promoter vs. constitutive promoter), gene structure (genomic copy vs. cDNA), and gene location (native location vs. ectopic location) on transcription levels 
of both ammonium transporters under low ammonium conditions compared to high ammonium conditions. Each construct was normalized to their parent strains that served as the baseline of expression.

Across the different ploidy constructs, I found that the diploid solopathogenic strain D132 had decreased expression of ump2 relative to the FB1 wild type strain under replete media conditions. D132 also increased its ump2 expression 8log2-fold when under low ammonium conditions as compared to itself under high ammonium conditions. The haploid solopathogenic strain SG200 showed an increase in ump2 expression compared to itself under low ammonium conditions and in high ammonium conditions in comparison to the FB1 wild type.

An SG200 $\Delta u m p 2$ mutant was used to test the roles of promoter type, gene structure, and gene location. Little difference in ammonium transporter transcription levels was observed compared to the FB1 wild type strain in replete media. Overexpression constructs had increased ump2 expression, as expected, and yielded a filamentous phenotype when under low ammonium conditions. SG200 $\Delta u m p 2$ mutants complemented with the various promoters driving the ump2 expression reestablished levels of expression, demonstrating that function was restored at the transcriptional level. When tested for ability to filament on low ammonium, such complemented strains restored the filamentation ability comparable to that of SG200 wild type strain. However, none of the strains expressing the over-expression constructs regained the fuzz phenotype on charcoal media or the ability to cause disease on maize, demonstrating lack of complementation of those phenotypes of the SG200 $\Delta u m p 2$ mutant. 


\section{TABLE OF CONTENTS}

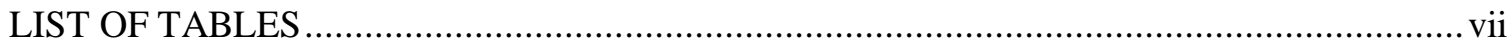

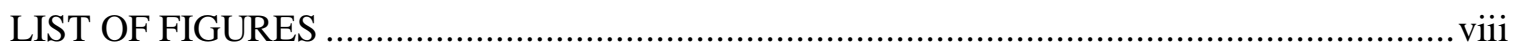

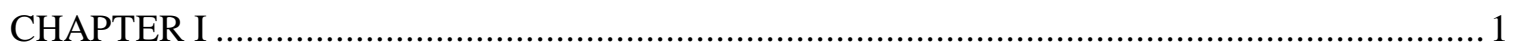

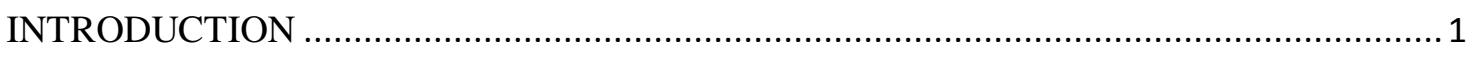

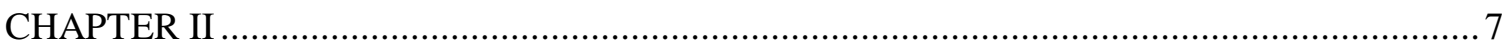

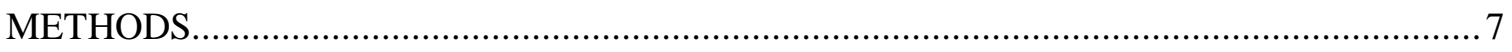

Cells and Growth Conditions..............................................................................

Constructs for altering expression of ump2 ................................................................ 7

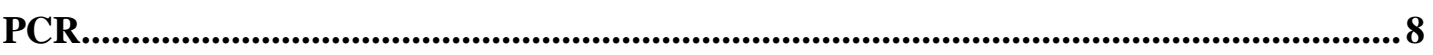

RNA Purification and cDNA Synthesis ...................................................................9

Primers for qRT-PCR ................................................................................................................. 10

qRT-PCR Analysis ...................................................................................................................... 10

Mating Assay and Plant Pathogenesis. ..................................................................................... 12

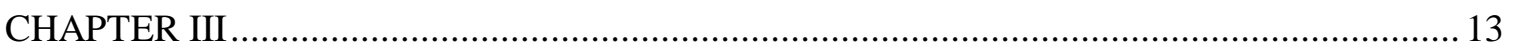

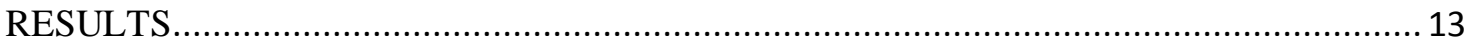

Effects of ploidy on transcription levels of ump2 and $u m p 1$..........................................13

Effects on transcription levels of ammonium transporters of altered ump 2 transcription levels and expression in different genomic contexts .................................. 14

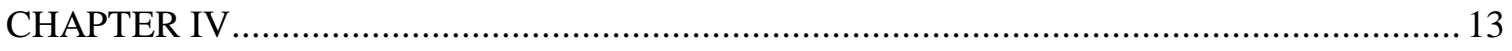

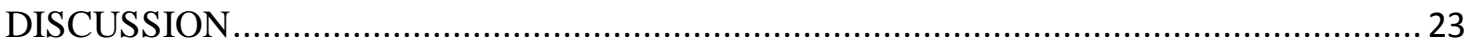

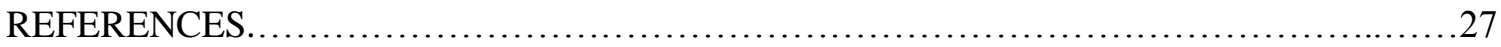

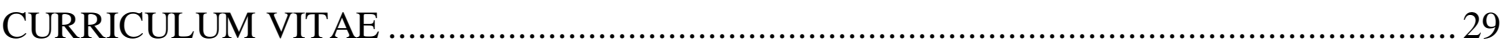




\section{LIST OF TABLES}

Table $\quad$ Page

1. U. maydis Strains Used in this Study ..................................... 8

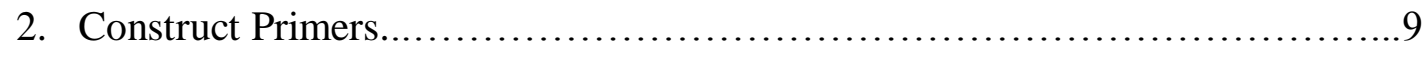

3. qRT-PCR Primers........................................................ 


\section{LIST OF FIGURES}

Figure $\quad$ Page

1. Tetrapolar Mating System..............................................

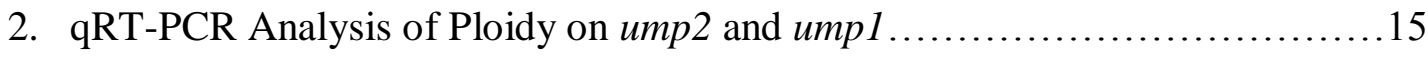

3. Filamentation on High vs Low Ammonium Conditions across overexpression and different genomic contexts......................................16

4. qRT-PCR Analysis of ump2 and umpl in Different Genomic Contexts.........19

5. SG200 Complementation: Cell Morphology under Low Ammonium Conditions

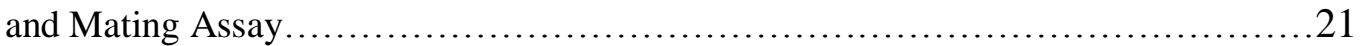

6. qRT-PCR Verification of Complementation by SG200 $\Delta u m p 2$ Strains

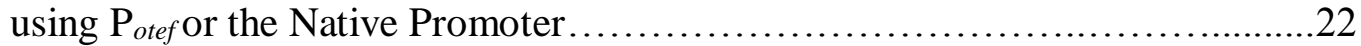




\section{CHAPTER I}

\section{INTRODUCTION}

Ustilago maydis is a basidiomycete responsible for the smut disease and gall formation in maize. U. maydis has a tetrapolar mating system that consists of two mating loci that are required for haploid partners to mate with their corresponding counterpart before downstream events, such as host infection, can take place (Djamei A, 2016). The two mating loci are locus $a$, which is the initial step in mating, and governs cell-cell recognition, and the $b$ locus which regulates further downstream events of sexual reproduction and pathogenic development. The $a$ locus has two variants, or idiomorphs, called a1 and a2 (Regenfelder E, 1997). Haploid cells possessing two opposite idiomorphs must come together to form a sexually compatible interaction. Each cell is responsible for the production of a pheromone and a receptor for the pheromone of the opposite mating-type cell. These idiomorphs are able to do this because they contain the genes for the structural pheromone precursor and for a receptor that can receive a signal from an opposite pheromone type. Successful interaction due to the pheromone response is the first hurdle that must be passed so that the components of the $b$ locus can check for additional aspects of compatibility.

Unlike the $a$ locus, for which there are only two different forms, the $b$ locus has more than twenty different alleles that can match up. If the allele in one cell is different than that of its partner, sexual reproduction will occur (Wahl R, 2010). If cells are 
successfully mated, the $b$ locus will lead to production

of proteins that form a heterodimer and cells will

produce a filamentous dikaryon. The two

homeodomain proteins, $\mathrm{bE}$ and $\mathrm{bW}$, that form the

heterodimer are required to maintain this filamentous

dikaryon structure and to allow the fungus to infect its

host (Banuette, 1994). As a whole, this complex

(shown in Figure 1) is essential in the production of

the heterodikaryon and to sustain cell proliferation to

further the pathogenicity.

Like all organisms, U. maydis requires a

variety of nutrients that it can obtain from its

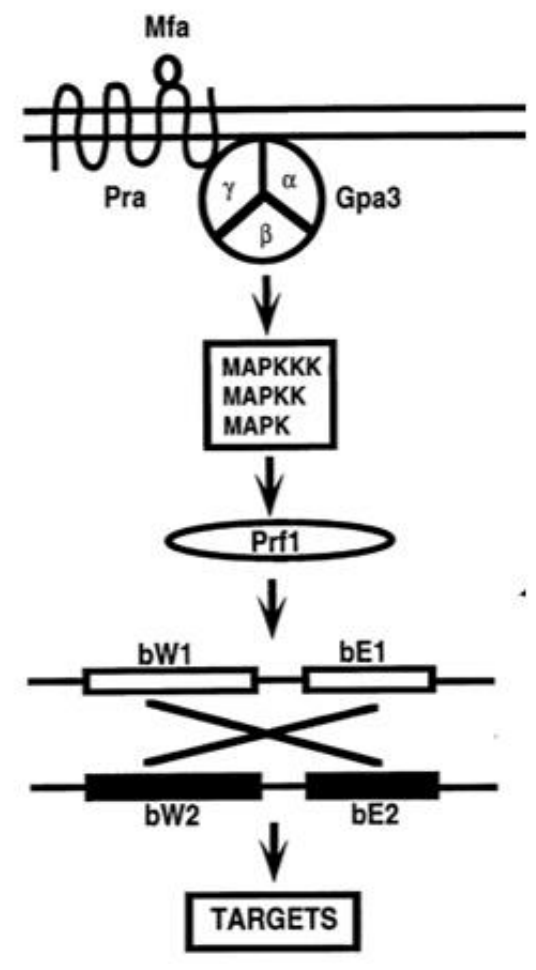

environment. One of these essential nutrients is

nitrogen. Ammonium is a vital nitrogen source

for fungi and plants, alike (Thomas, 2012).

Each cell must have the ability to take up

ammonium in order to carry out cellular

functions required for life, not to mention

pathogenicity and virulence, in the case of

Figure 1: Tetrapolar Mating System:

This schematic represents the pheromone mating pathway in general terms. From the top, the receptor receives a signal from the pheromone, in the environment that had been released from another Ustilago maydis cell. Once the opposite idiomorphs come together, the $b$ locus interacts and, if compatible, will encode for transcription factor necessary for pathogenicity and virulence.

pathogenic yeast and fungi. Initially, the transmembrane ammonium transporters, Mep1, Mep2 and Mep3, were characterized in the model yeast, Saccharomyces cerevisiae. Each has its own affinity for ammonium, but Mep2 in particular is an ammonium permease with the highest affinity for ammonium of the three transporters (Julian Rutherford, 2008; 
Marini, 1997). Mep3 has the lowest affinity, with no significant difference in ammonium uptake than a triple mep1mep2mep3 deletion strain, although it does transport enough ammonium to sustain the life of the species in very low ammonium conditions. Of the three, Mep2 has been termed a "transceptor," since it is not only able to transport ammonium, but is also responsible for sensing the available ammonium in the environment around the cell. Due to this sensing ability, Mep2 is also required for the induction of filamentous growth as a response to low nitrogen. Neither Mep1 nor Mep3 have the ability to sense the available ammonium around the cell, so in mep2 deletion strains, there is no transition to a filamentous growth stage.

Similar to the yeast ammonium transporters in S. cerevisiae, U. maydis has two ammonium transporters that behave similarly to the yeast model, ump2 and umpl(Smith, 2003). The response to low ammonium of haploid cells (i.e., filamentous growth) only requires one of these transporters, Ump2, the high-affinity transporter. ump2 deletion strains are unable to filament when starved for ammonium as opposed to the wild type cells that do filament when in starvation conditions. As for umpl deletion strains, there is no phenotypic change. Interestingly, it has been shown that the wild type phenotype for S. cerevisiae strains deleted for mep1, mep2 and mep3 can be restored when ump2 is expressed in such mutants, allowing for ammonium transport and sensing to occur (Smith, 2003). The exact mechanism behind ump2 driving filamentous growth is still not fully understood, but the mitogen-activated protein kinase (MAPK) and cAMP-dependent PKA (protein kinase A) signaling pathways are known to affect filamentous growth. It has been theorized that ump2 interacts with the PKA signaling pathway, so this may be a lead into how this mechanism works (Pham, 2009). 
Ploidy refers to the number of chromosome sets within a cell of an organism. The number of chromosome sets can change for various reasons such as during fertilization, where this number would double, or during meiosis, in which ploidy is halved (Galitski, 1999). Characteristically, cells with different ploidy levels will show different morphological and physiological characteristics. In S. cerevisiae, when opposite mating

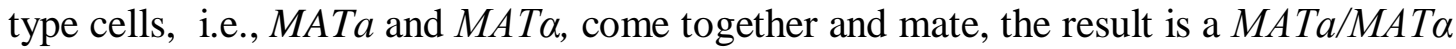
diploid cell (Haber, 2012). The original haploid cells and the newly mated cells each have different phenotypes, likely the direct result of their different genotypes which control expression of specific genes in diploids. There may be additional effects on phenotype due specifically to ploidy.

Most of our understanding of the importance and consequences of ploidy has been obtained through plant models and some animal models (Albertin, 2012). Interestingly, the effects of ploidy in most other eukaryote kingdoms, including fungi, still remain mostly unknown. In maize, global gene expression was analyzed across strains/cultivars with a variety of different total number of ploidy levels and found few significant differences on the gene expression within the plant (Riddle, 2010). The change in ploidy affects a large portion of expression for the maize genome, but at very low levels, i.e., typically under a two-fold change.

One goal of this thesis is to further investigate how expression of the ammonium transporter genes, ump1 and ump2, changes in various ploidy backgrounds of $U$. maydis. Quantitative real-time polymerase chain reaction (qRT-PCR) analysis was used to quantify gene expression at the level of transcription in mutant strains in comparison to the FB1 wild type strain. 
The second goal of this study was to further investigate the gene expression of the ammonium transporters, umpl and ump2, in U. maydis in association with various overexpression constructs and genetic backgrounds. qRT-PCR analysis was again used to quantify gene expression in mutant constructs in comparison to the wild type progenitor strain. Plant infections were also used to examine any phenotypic difference in pathogenicity in the FB1 and SG200 backgrounds.

As part of this second goal, I was also interested in examining how gene structure and genomic context might influence gene expression. For this reason, I compared ump2 constructs using cDNA versus gDNA to determine the difference in the ammonium transporter gene expression. cDNA is reverse transcribed from the mRNA of interest (Candy Taylor, 2016). These constructs would lack the intron region of the initial transcript which can sometimes play a role in regulating gene expression. Conversely, gDNA (genomic DNA) would include both the exons and the introns. Since gDNA contains the entire genomic sequence, there are other factors that can play a role in gene expression (James Yun, 2006). Such factors that can affect gene expression or be used as critical component of regulation include the 5' untranslated region (UTR) and 3'-UTR. The 5'-UTR, the region just upstream of the initiation codon, has been shown to affect expression in S. cerevisiae (Hoshida H., 2016). Within this region, there is potential for an intron promoter to exist, that can change expression from the native promoter. In $S$. cerevisiae, an intron promoter was found to increase expression from one of the strongest promoters, TDH3p, when tested. As for 3'-UTR, the region following the termination codon, there may be additional regulatory units present. This includes, but is not limited to, regulatory units that may influence translation efficiency, binding sites that, when 
bound, can decrease gene expression or degrade the transcript, and alternative polyadenylation sites. In mouse Thy $1+$ germline cells, it has been found that particular sequence patterns in the 3' UTR length can affect gene expression both by upregulation or downregulation (Huang, 2015). This change can have an impact on the stability of the RNA, which would, in turn, affect gene expression. Thus, the roles of 5'- and 3'-UTRs were also examined in ump 2 constructs, so as to assess their importance in both transcription levels of ammonium transporters and also their ability to confer full phenotypic function associated with wild type expression of the ump2 gene. 


\section{CHAPTER II}

\section{METHODS}

\section{Cells and Growth Conditions}

U. maydis strains used in this study are listed in Table 1. U. maydis strains were grown in YPS or on high ammonium Array Media [AM] (6.25\% Holliday Salt Solution [20], 1\%

glucose, $30 \mathrm{mM}$ Glutamine/50 mM Ammonium sulfate and 2\% agar) and Array Medium [AM] with low ammonium (6.25\% Holliday Salt Solution, $1 \%$ glucose, $50 \mu \mathrm{M}$ ammonium sulfate and $2 \%$ agar) at room temperature. All mutant strains were generated in either the FB1 or SG200 backgrounds. FB1 is a wild type haploid strain, while SG200 is a genetically engineered haploid strain that constitutively expresses the bE1/bW2 heterodimer, and is thus solopathogenic (Kamper, 2006).

\section{Constructs for altering expression of $u m p 2$}

When overexpressing and deleting ump2 in $U$. maydis, constructs were obtained via homologous recombination as previously described (Brachmann, 2001). The $\Delta u m p 2$ construct was created using the pimers Ump2KOup5' and Ump2_Dn_TapR (sequences listed in Table 2 below). As for the ump2 overexpression construct, the ump2 ORF cDNA copy was amplified using the primers Ump2_CGO5' and Ump2_CGO3'. This fragment was then cloned into pCR2.1 TOPO (Invitrogen). Further strains were generated to provide constitutive expression of ammonium transporter genes via the 
Table 1. $U$. maydis Strains Used in this Study

\begin{tabular}{|c|c|c|}
\hline Strain & Genotype & Source \\
\hline FB1 WT & $a 1 b 1$ & (Banuette, 1994) \\
\hline SG200 & a1 mfa2 bW2bE1 & (Kamper, 2006) \\
\hline D132 & $a 1 / a 2 b 1 / b 2$ & (Garcia-Pedrajas, 2010) \\
\hline SG200 $\Delta u m p 2$ & a1mfa2 bW2bE1 ump2::hygR & This Study \\
\hline SG200 $\Delta u m p 2 P_{\text {otet }}$ ump2 & a1mfa2 bW2bE1 Potef-ump2 & This Study \\
\hline SG200 $\Delta$ ump2 $\mathrm{P}_{\text {uтр } 2}$ & a1mfa2 bW2bE1 Pump2 & This Study \\
\hline FB1 $\Delta u m p 2 \mathrm{P}_{\text {ump2 }} \mathrm{CDNA}$ & a1b1 Pump2 & This Study \\
\hline FB1 $\triangle$ ump2 $\mathrm{P}_{\text {otef }}$ ump2 gDNA & a1b1 Potef-ump2 gDNA & This Study \\
\hline FB1 $\mathrm{P}_{\text {ump2 }}+$ Coding Region & $a 1 b 1$ Pump2 $+C R$ & This Study \\
\hline FB1 P $P_{\text {otef }}$ & a1b1 Potef-ump2 & This Study \\
\hline FB1 $\triangle$ ump2 $\mathrm{P}_{\text {otef }}$ ump2 & a1b1 Potef-ump2 & This Study \\
\hline SG200 $\Delta$ ump2 $\mathrm{P}_{\text {ump2 }}+\mathrm{CR}+3^{\prime}$ UTR & a1mfa2 bW2bE1 Pump2 & This Study \\
\hline
\end{tabular}

constitutively active $\mathrm{P}_{\text {otef }}$ promoter. Ump2 was cloned downstream of the $\mathrm{P}_{\text {otef }}$ promoter in the p123 (Otef) vector which is the vector used to confer resistance to carboxin after first linearizing the vector using the $S s p 1$ restriction enzyme. U. maydis was then transformed and plated on selectable marker media to find recombinants that had carboxin resistance. One construct was designed using genomic DNA instead of cDNA as the source of the ump2 gene. Mutants were complemented via cloning the ump2 ORF into the Otef vector either with the native promoter or by having transcription of ump2 driven by the constitutive $\mathrm{P}_{\text {otef }}$ promoter already present in the vector. PCR was performed after each construct was generated to ensure to verify the construct size.

\section{PCR}

PCR was performed using either the PTC-100 Programmable Thermal Controller or the Bio Rad T100 Thermal Cycler. The cycle conditions utilized a denaturation temperature of $94{ }^{\circ} \mathrm{C}$ for 4 minutes, proceeded by 34 cycles of a three-step process beginning with a 
temperature of $94{ }^{\circ} \mathrm{C}$ for 30 seconds, annealing at a temperature between $55{ }^{\circ} \mathrm{C}$ to $64{ }^{\circ} \mathrm{C}$ and ending with an extension period at $72{ }^{\circ} \mathrm{C}$ for 1 minute. A final extension was performed at $72{ }^{\circ} \mathrm{C}$ for 10 minutes to end this reaction. Ex-Taq Hot Start DNA polymerase (Takara) was used to catalyze these reactions.

\section{Table 2: Primers used for overexpression construct}

\begin{tabular}{|l|l|}
\hline Primer Name & Sequence \\
\hline Ump2KOup5' & GGCAAGACAAGACGAGAAGA \\
\hline Ump2_Dn_TapR & TGCGTGTCTCAAACTCCTCT \\
\hline Ump2_CGO5' & ATTAACCGCGGAAATGGTTAACGCCAGCTAC \\
\hline Ump2_CGO3' & TGATTGCGGCCGCTTAGACAGCAGTAGGCTG \\
\hline
\end{tabular}

\section{RNA Purification and cDNA Synthesis}

Methods used to extract RNA from cells were based on the RNeasy Plant Mini Kit (Qiagen, cat no. 74903) with a few variations for more purified yield of RNA. Cells were grown on appropriate plates for 48 hours before they were scraped off the plate and ground into a powder on ice in a mortar and pestle that had been chilled at least overnight at $-80{ }^{\circ} \mathrm{C}$. All steps followed the RNeasy Plant Mini Kit protocol until the wash steps; to ensure a pure and uncontaminated yield, three gentle 'flicks' towards the bottom of the column were performed to remove residual ethanol. Additionally, a ten minute drying period was added before elution of the RNA to allow for less ethanol contamination. Sample purity was assessed with the NanoDrop 2000 UV-Vis Spectrophotometer. Concentrations above $80 \mathrm{ng} / \mathrm{ml}$ were considered high enough to continue processing. cDNA was synthesized using SuperScript III First-Strand Synthesis System (Invitrogen, 
Cat no. 18080-51). Sample purity was assessed again with the NanoDrop 2000 UV-Vis Spectrophotometer. Protein and organic contamination was also measured with an ideal range of $1.8-2.2(260 / 280$ and $260 / 230$ ratio).

\section{Primers for qRT-PCR}

Primers used for qRT-PCR are shown in Table 3 below. These were designed using ABI Primer Express software version 3.0. All other primers were designed using Primer3 software. Primers were ordered from and synthesized by Eurofins Genomics (Louisville, $K Y)$.

Table 3: qRT-PCR Primers

\begin{tabular}{|c|c|l|}
\hline Primer Name & Forward/Reverse & \multicolumn{1}{c|}{ Sequence } \\
\hline eIF2 & Forward & 5'-CAAATGCGATCCCGAACAG-3' \\
\hline & Reverse & 5'-TGGGACACCACTTGTCAAGCA-3' \\
\hline ump2 & Forward & 5'-TGGGTCCCGTTCTCATTTTC-3' \\
\hline & Reverse & 5'-AGGGGATGGGATTGTAGACAA-3' \\
\hline ump1 & Forward & 5'-CGGTCTCACCTGGATGTTCCT-3' \\
\hline & Reverse & 5'-AGCCAACGACGGACCACTT-3' \\
\hline
\end{tabular}

\section{qRT-PCR Analysis}

qRT-PCR was performed using the AB Applied Biosystems StepOne Real-Time PCR System. Non-specific detection was observed using SybrGreen as the florescence. qRTPCR utilized an initial denaturation temperature of $95^{\circ} \mathrm{C}$ for 10 minutes, followed by 35 2-step cycles beginning with a temperature of $95{ }^{\circ} \mathrm{C}$ for 15 seconds, $60{ }^{\circ} \mathrm{C}$ for 1 minute, followed by the dissociation curve with settings at $95{ }^{\circ} \mathrm{C}$ for 15 seconds, $60{ }^{\circ} \mathrm{C}$ for one minute and $95{ }^{\circ} \mathrm{C}$ for another 15 seconds. Melting curve analysis was performed at the end of each cycle to ensure specificity of the reaction. The concentration was determined 
by the comparative CT method (threshold cycle number at the cross point between amplification plot and threshold) and values were normalized to expression of the constitutively expressed gene, eif $2 B$ (unchanged in RNA-Seq analysis), encoding the translation initiation factor eIF2. Changes in the gene expression are averages of at least three biological replicates and are displayed as $\log 2$-fold changes relative to expression of wild type FB1 under high ammonium condition or as a comparison of the respective mutant at high and low ammonium. For statistical analysis of qRT-PCR results, first the transcript level of each target for each mutant in low vs high ammonium conditions was compared, using Kruskal Wallis (Daniel, 1990). Second, the absolute transcript level for each mutant under each conditions was compared to that for FB1 wild type under the same condition. So, all the mutants on high ammonium were compared to wild type on high ammonium and then all the mutants on low ammonium were compared to the wild type on low ammonium. This analysis again used Kruskal-Wallis, as we assume these do not vary normally. Third, analysis of covariance on all of the changes for high to low ammonium. This analysis corrects for any variations within biological replicates of each mutant and sets the "control" (in our case high Ammonium) to zero, and then looks at the absolute increase or decrease in transcript level based on these corrections. All gene expression was normalized against FB1 wild type on high ammonium or to SG200, depending on whether the comparison was for ploidy effects or relative expression for mutants derived from a particular background progenitor strain. 


\section{Mating Assay and Plant Pathogenesis.}

Strains were grown in YPS overnight and then densities were measured with a spectrophotometer. Cultures were diluted to an absorbance at $600 \mathrm{~nm}$. Strains then continued to grow for approximately 4 additional hours to an absorbance at $600 \mathrm{~nm}$ of between 0.5 and 0.7. Golden Bantam corn seedlings were grown to 8 to 10 days and then infected via a syringe into the stem. Virulence was measured on a scale of 0 to 5 depending on the symptoms present after 7 days, 9 days, and 14 days post-infection. Scale ratings were 0 meaning a healthy plant after infection, 1 for chlorosis, 2 for small galls present on the plant leaves, 3 for small galls on both the leaves and plant stem, 4 for larger galls and 5 representing a dead plant. Ratings were averaged among each group infected and Kruskal-Wallis Test with Multiple Comparison (Daniel, 1990) was used for statistical analysis of the infection rating. 


\section{CHAPTER III}

\section{RESULTS}

\section{Effects of ploidy on transcription levels of ump2 and ump1}

U. maydis strains with different chromosomal ploidy levels showed differences in gene expression of ammonium transporters. The FB1 wild type (Banuette, 1994), a haploid strain, was used as the comparison strain against two solopathogenic strains. These solopathogenic strains have the ability to infect their host plant in the absence of mating with a compatible haploid partner. D132 (Garcia-Pedrajas, 2010), a diploid solopathogenic strain, and SG200 (Kamper, 2006), a haploid solopathogenic strain, were used for this comparison.

qRT-PCR provides the opportunity to explore differential gene expression, in this case, of the ammonium transporters in U. maydis, ump2 and umpl. These data allowed me to evaluate transcription levels of these two target genes against the FB1 wild type strain in both high and low ammonium conditions.

High ammonium conditions resulted in differential gene expression of both ammonium transporters in the diploid solopathogenic strain, D132 and the haploid solopathogenic strain, SG200 compared to wild type FB1 under the same conditions. The expression of ump2 in D132 was substantially reduced, roughly $6 \log 2$ fold lower compared to the FB1 wild type strain (Figure 2A). As for umpl in D132, gene expression was also significantly reduced, a $5 \log 2$ fold change $(\mathrm{p}<.05)$. Compared with 
FB1 wild type in high ammonium conditions, SG200 had increased expression of ump2 and reduced expression of $u m p l$, both of which were statistically significant ( $\mathrm{p}=.05)$.

Low ammonium conditions in D132 resulted in a downregulation of ump2 expression compared to the FB1 wild type under high ammonium conditions according to the Kruskal-Wallis one-way analysis of variance $(\mathrm{p}=.05)$ (Figure 2B). As for the SG200, there was a 'trend towards' differential expression $(\mathrm{p}=.06)$ for $u$ ump 2 but none of the observed changes were statistically significant.

When comparing each strain with itself when grown on low ammonium vs. replete media, D132 showed significant differences in gene expression $(\mathrm{p}=.05)$ (Figure 2C). The $\log 2$ fold change in ump 2 on low ammonium compared to replete medium was significant as was that for umpl. FB1 wild type showed this same trend, though the induction in D132 was greater than that in FB1. SG200 also showed statistical significance in its induction from high to low ammonium conditions with a $5 \log 2$ fold change, similar to that in the FB1 and D132 strains. Overall, both the diploid and haploid solopathogenic strains, D132 and SG200, respectively, exhibited changes in ammonium transporter gene expression due to different ploidy levels.

\section{Effects on transcription levels of ammonium transporters of altered ump2}

\section{transcription levels and expression in different genomic contexts}

Higher concentrations of ammonium block filamentation in C. albicans when the high affinity transporter was over-expressed (Biswas, 2014). Conversely, in $S$. cerevisiae, increasing the expression of the high affinity ammonium transporter, Mep2, led to pseudohyphal growth, even under non-inducing conditions (Julian Rutherford, 2008). In this portion of the study, I explored the role of ump2 expression constructs on 

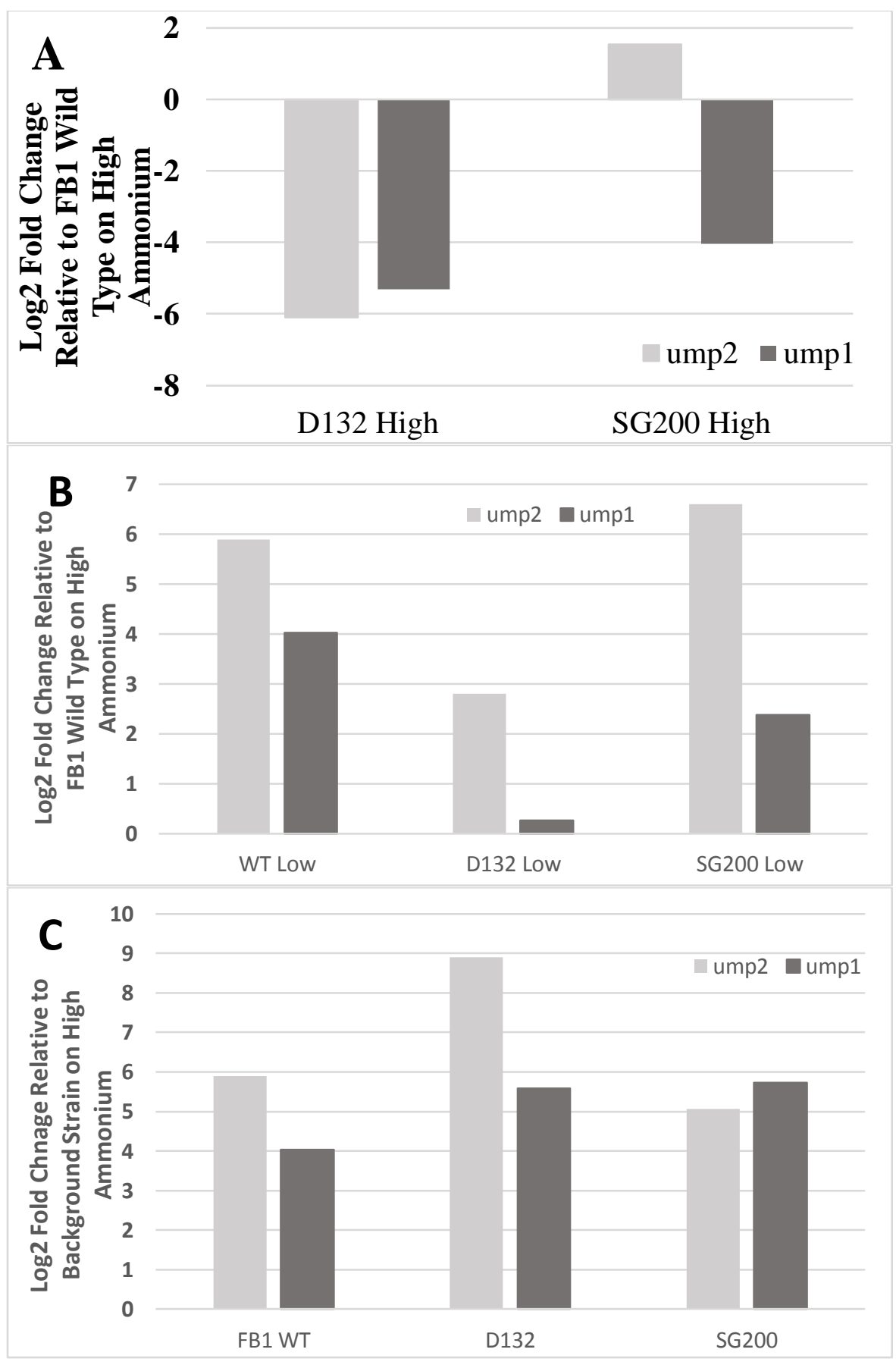

Figure 2: qRT-PCR analysis of ploidy on ump2 and ump1. The FB1 wild type strain shows increased expression of ammonium transporters from high to low ammonium conditions. D132, diploid solopathogenic strain, and SG200, haploid solopathogenic strain, show differences in transcript level in comparison to FB1 wild type strain. A) qRT-PCR Log2 fold changes of ump2 and $u m p l$ of solopathogenic strains grown in replete media for $48 \mathrm{hr}$; changes are shown relative to the haploid FB1 wild type strain. B) $\log 2$ fold changes of ump2 and ump1 of FB1 wild type and solopathogenic strains in ammonium deficient media relative to FB1 in replete media. C) $\log 2$ fold changes of ump2 and ump1 for each strain in ammonium deficient media relative to the same strain in replete media. 
filamentation in $U$. maydis. In $U$. maydis, FB1 wild type cells grow via budding, yielding smooth colonies under replete media conditions (Figure 3). When grown in ammonium deficient conditions on solid media, FB1 cells produce filamentous colonies; FB1 cells with the ump2 overexpression construct yielded a widespread filamentous growth within two days as opposed to four days in the FB1 wild type cells. Figure 3 shows that all strains had a smoother colony morphology under high ammonium, though the strain bearing ump2 over-expressed from the constitutive $P_{\text {otef }}$ promoter showed some filamentation, under even these, normally non-inducing conditions. On the other hand, while all strains filamented on low ammonium, strains with constructs in which $P_{\text {otef }}$ was driving ump2 expression showed hyperfilamentation under these conditions; this was true regardless of the structure of the ump2 ORF provided (i.e., cDNA or gDNA).

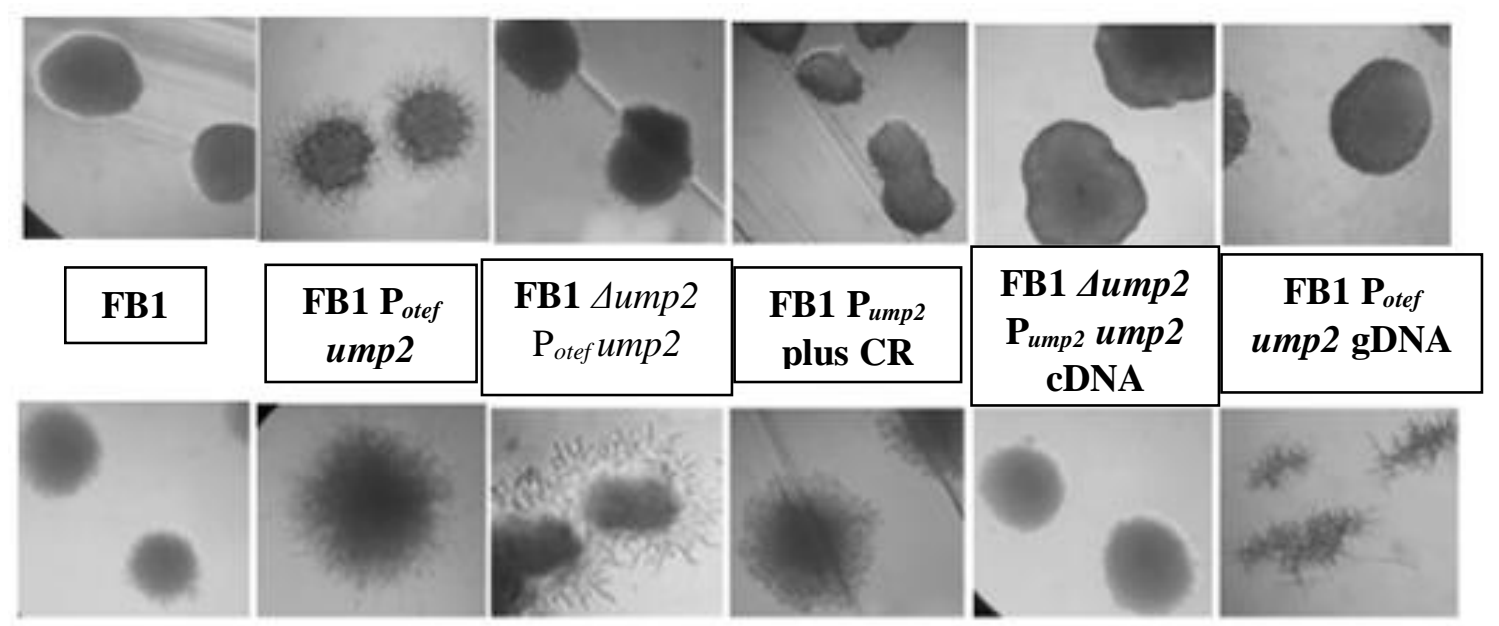

Figure 3: Filamentation on High vs Low Ammonium Conditions across overexpression and different genomic contexts. Top row shows each strain in high ammonium conditions while the bottom row shows the same strains in low ammonium conditions (all images are after four days growth under the respective conditions). Strains are FB1 wild type, FB1 $\mathrm{P}_{\text {otef }}$ ump2, FB1 4 ump2 $\mathrm{P}_{\text {otef }}$ ump 2, FB1 $\mathrm{P}_{\text {ump } 2}$ plus coding region (CR), FB1 4 ump2 $\mathrm{P}_{\text {ump } 2}$ ump 2 cDNA and FB1 $\mathrm{P}_{\text {otef }}$ ump2 gDNA, respectively. 
Furthermore, I explored the role of ump2 transcription levels in various overexpression constructs and different genomic contexts using qRT-PCR analysis. Three overexpression constructs were designed: FB1 $P_{\text {otef }}$ ump 2 containing the native copy of ump2 as well as a copy at the ip locus driven by the constitutively active promoter, $P_{\text {otef; }}$ FB1 1 ump $2 P_{\text {otef }} u m p 2$ containing only one copy of $u m p 2 \mathrm{cDNA}$ at the ip locus driven by the constitutively active $P_{\text {otef; }}$ FB1 Pump $2+$ coding region, containing two copies of ump2, one at the native locus and a second cDNA coding region driven by the native promoter as well, again integrated at the ip locus. qRT-PCR results showed that all three constructs upregulate ump2 gene expression in replete medium (Figure 4A). Umpl expression varied slightly, as it was upregulated in all but the FB1 $\mathrm{P}_{\text {otef }}$ ump2, in which it was down regulated in comparison to FB1 wild type. When low ammonium conditions were compared to FB1 wild type under high ammonium conditions (Figure 4B), there was an upregulation in ump2 across all the strains. When each mutant construct under low ammonium conditions was compared to itself in high ammonium conditions, there was an increase in $u m p 2$ in each construct. The biggest difference of note is the strain FB1 $\Delta u m p 2 P_{\text {otef }}$ ump2 (Figure 4C), in which ump1 was downregulated in comparison to the other overexpression constructs. This suggests that when the $P_{\text {otef }}$ promoter was the sole promoter driving ump2, that ump1 may be more downregulated.

Two different genomic contexts were investigated to explore other possible regulators outside of the coding region of the construct. FB1 $\Delta u m p 2 P_{u m p 2}$ cDNA strain lacked its native copy of ump2 while the cDNA copy of ump2 driven by its native promoter was cloned into the ip locus. Conversely, an overexpression gDNA construct was designed, FB1 $P_{\text {otef }}$ ump 2 gDNA, which contained the exons and intron of ump2 
driven by the constitutively active promoter. Similarly, qRT-PCR revealed that both ammonium transporters were upregulated on high ammonium in comparison to the FB1 wild type strain. ump2 and umpl were both upregulated in low ammonium conditions as well. FB1 $\triangle$ ump2 $P_{\text {итр} 2 ~}$ cDNA strain showed nearly 4log2-fold increased transcript levels for ump2 on low ammonium relative to the same strain grown on replete ammonium conditions. The data suggest that the cDNA construct actually induced ump2 expression more than the gDNA copy did. This suggests that there may be some other regulatory component within the introns that affects the expression of ump2. When each construct under low ammonium conditions was compared to itself under high ammonium conditions (Figure 4C), the cDNA construct had an upregulation of ump2 and very little change in ump1. In the strain using the ectopic gDNA copy, ump2 expression was downregulated, though this low of a fold change actually suggests no change in expression under high and low conditions. This also applies to the small up regulation in umpl which suggests no change in expression.

\section{Deletion of ump2 in a solopathogenic strain eliminates filamentation on low ammonium, fuzz on charcoal medium, and pathogenicity.}

Deletion of ump2 (or both ump1 and ump2) in haploid strains (i.e., FB1 and FB2) had previously been observed to have negative effects on filamentation on low ammonium and on pathogenicity (Jinny Paul, 2014). Given these observations, we wanted to examine whether these effects would be also seen in a haploid strain whose pathogenicity does not require mating and fusion of compatible haploids. When the ump2 deletion mutant was produced in the solopathogenic haploid strain SG200 (Kamper, 


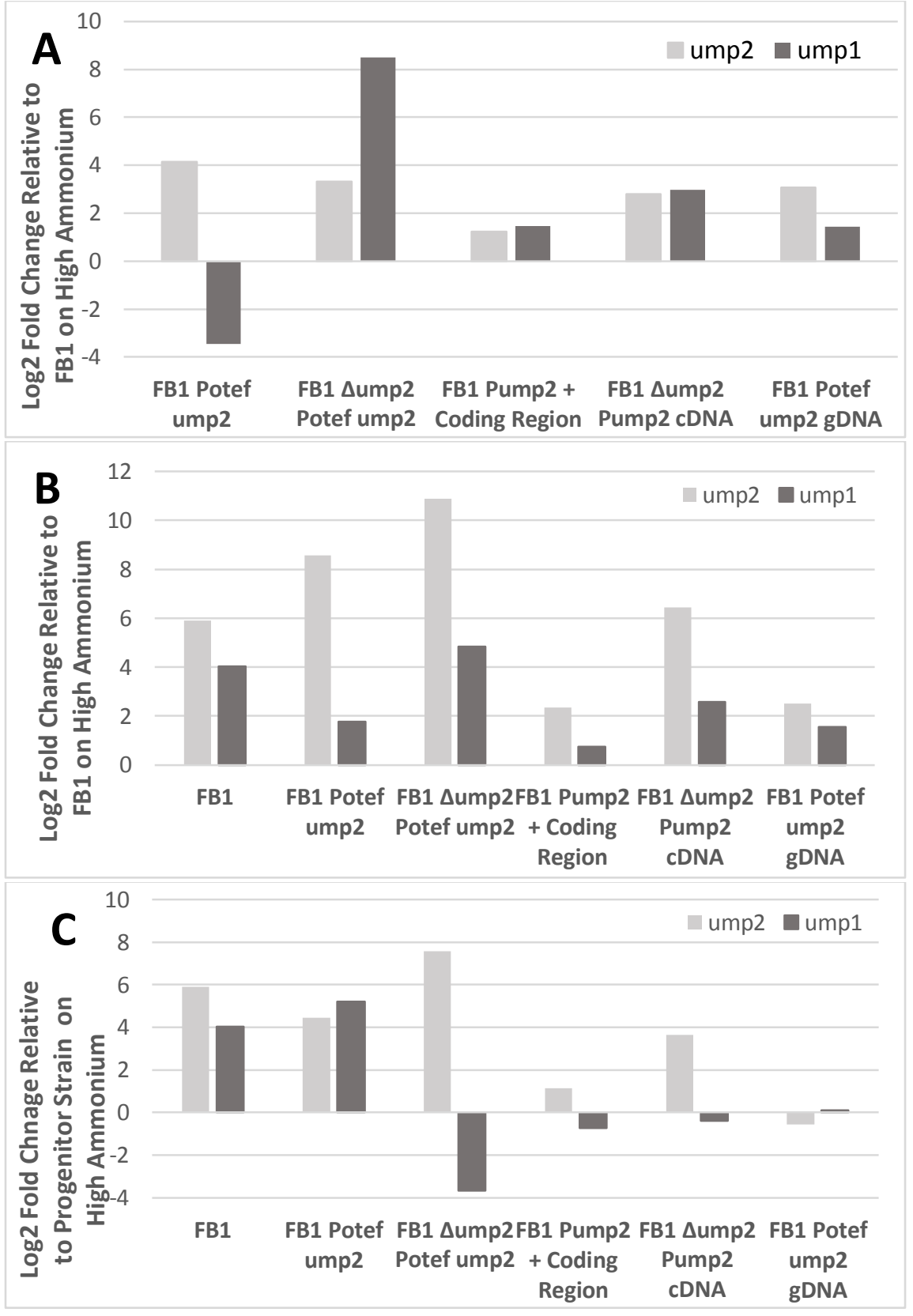

Figure 4: qRT-PCR analysis of ump2 and ump1 in different genomic contexts. Ump2 overexpression constructs and different genetic backgrounds show an increase in transcript level in comparison to FB1 wild type strain. All strains were grown in ammonium replete or deficient media, as indicated, for $48 \mathrm{hr}$. A) qRT-PCR Log2 fold changes of transcription relative to the wild type FB1 strain, of ump2 and ump 1 for different ump2 genomic contexts grown in replete medium. B) Log2 fold changes relative to FB1 in replete media of ump2 and umpl of FB1 wild type and strains with different $u m p 2$ genomic contexts when grown in ammonium deficient media. C) $\log 2$ fold change of ump2 and ump1 for strains with different ump2 genomic contexts in ammonium deficient media relative to that for the same strain in replete media. 
2006), this strain also failed to filament on low ammonium. (Fig. 5a). The SG200 strain is a solopathogenic strain commonly used for plant pathogenicity experiments as it allows infectious filament formation and successful completion of the lifecycle in planta. This strain normally produces the "fuzz" reaction on charcoal media. Surprisingly, when the ump2 gene was deleted in this background, the resulting strain failed to display aerial hyphae on charcoal plates (Fig. 5b). Two independent strains complemented for ump2 in the SG200 Dump2 mutant were produced using either the native promoter or Potef to drive ump2 expression. Both strains showed complementation of the filamentation defect on low ammonium (Fig. 5a). However, in contrast, neither strain displayed wild type levels of aerial hyphae production on charcoal media (Fig. 5b).

To evaluate whether the apparent defect in pathogenicity observed in the dikaryon experiments above could be replicated in strains that did not require mating prior to infection, again the SG200 strain was used. In this case, defects in pathogenicity due to ump1 or ump2 could be assessed independently of the initial mating process. The results are presented in a percent of symptom formation graph (Fig. 5c). Significantly more healthy plants survived at the end of the study in the group that was infected with the SG200 Dump2 mutant or the SG200 ump1 ump2 double mutant (not shown) and in most of the plants ( $63-83 \%)$, the fungus was unable to progress in infection even to stage 1 (chlorosis) (Fig. 5c). Two independent strains complemented for ump2 in the SG200 Dump2 mutant with either the native promoter or the Potef to drive ump2 expression both failed to generate wild type levels of virulence (Fig. 5c). 
Figure 6 provides evidence that both constructs yielded wild type or above expression levels of transcription for ump2, thus ruling out the possibility that the complemented strains were not expressing the introduced trans copies of that gene.

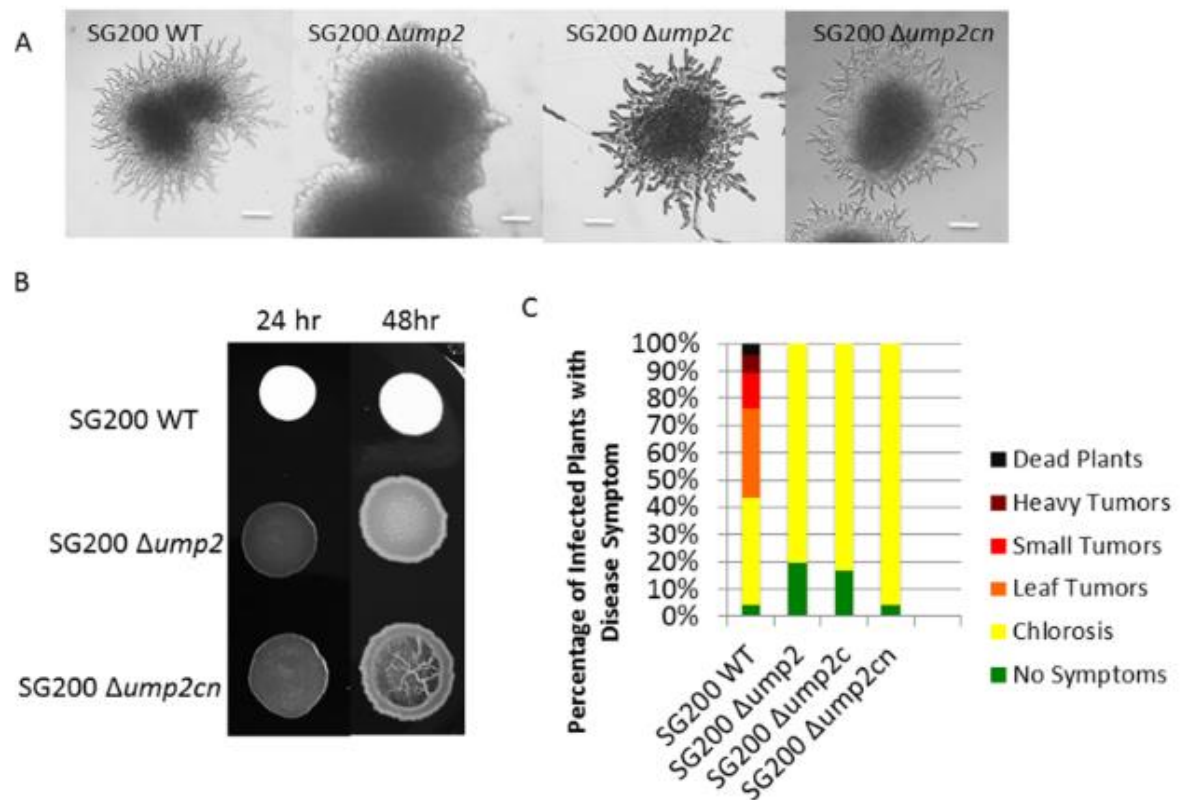

Fig. 5. SG200 Complementation: Cell Morphology under Low Ammonium Conditions and Mating Assay. Deletion of ump2 in a solopathogenic haploid strain eliminates filamentation due to low ammonium, but also the fuzz phenotype on charcoal, and is associated with loss of virulence on maize. (A) SG200, SG2004ump2, SG200 Aump2 complemented strains. On AM low ammonium, for $48 \mathrm{~h}$. Size bars, $200 \mu \mathrm{m}$. (B) Approximately $10^{6}$ cells from mid-log phase

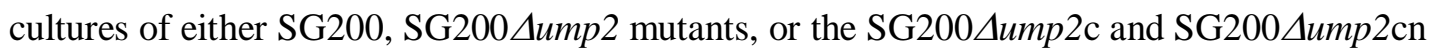
derivatives were spotted onto PDA charcoal medium and allowed to grow for $24 \mathrm{~h}$ and $48 \mathrm{~h}$ at $26^{\circ} \mathrm{C}$. (C) Disease symptom formation in the U. maydis SG200 mutant strains. All strains were rated at 10 days post-infection. Plants were inoculated with one background, indicated on the $\mathrm{X}$ axis. A disease index (DI; [30]) was used initially to rate virulence of each infection, with $0=$ no symptoms/ healthy plants, $1=$ chlorosis and / or anthocyanin production, $2=$ small leaf galls, $3=$ small leaf and stem galls, $4=$ large galls and $5=$ plant death. Diseases rating for the plants were obtained after 7, 10,14, 17, and 21 days post infection (dpi) and the disease indices for each strain were averaged to get a DI measure per strain. The graphs display the percentage of plants with specific symptoms of infection. 


\begin{tabular}{|c|c|}
\hline Strain & $\begin{array}{l}\text { qRT-PCR Log2 Fold Change of ump2 Expression relative to } \\
\text { SG200 WT on Low Ammonium }{ }^{\mathrm{a}}\end{array}$ \\
\hline SG200 & $1.00 \pm 0.09$ \\
\hline SG200 $\Delta u m p 2$ & $-9.76 \pm 0.13$ \\
\hline SG200 Аump2 Potef ump2(c1) & $3.07 \pm 0.06$ \\
\hline SG200 Аump2 Pump2 ump2(c2) & $1.01 \pm 0.03$ \\
\hline
\end{tabular}

B

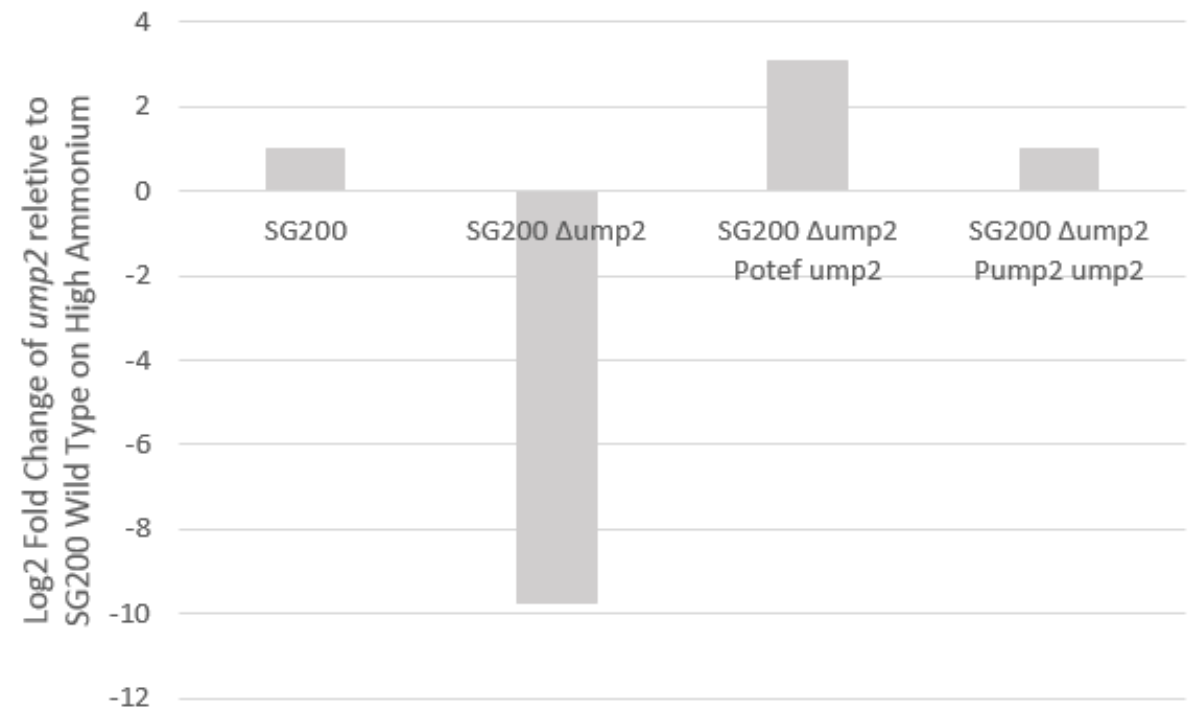

Figure 6. qRT verification of ump2 transcription in SG200 $\Delta u m p 2$ strains provided the gene ectopically driven by $\boldsymbol{P}_{\text {otef }}$ or the native promoter. Both complement constructs, with $P_{\text {otef }}$ and with the native promoter driving ump2 expression, demonstrated expression levels of ump2 similar to that of the wild type when all three were tested under low ammonium conditions. A) qRT-PCR Log2 fold changes of ump2 of mutant strains relative to SG200 wild type on low ammonium $^{\text {a }}$, plus/minus standard error across technical replicates. B) Graphical representation of qRT-PCR $\log 2$ fold changes of mutants relative to SG200 wild type on low ammonium ${ }^{\text {a }}$.

${ }^{\mathrm{a}}$ Low ammonium is $50 \mu \mathrm{M}$ ammonium and $1 \%$ glucose by volume. 


\section{CHAPTER IV}

\section{DISCUSSION}

U. maydis is a basidiomycete fungus that exhibits a dimorphic switch from a yeast-like state to a filamentous growth state. This switch changes the fungus from a saprophytic stage to a pathogenic stage, infecting mainly Z. mays. This switch is triggered due to different environmental conditions, such as nutrient limitation. Nitrogen limitation, specifically ammonium, is one factor responsible for this switch, yielding either dikaryon formation for mated haploid cells, or a filamentous phenotype for haploid cells not engaged in mating. There are two genes encoding ammonium permeases in $U$. maydis responsible for transporting ammonium into the cell; ump2 and ump1. Ump2, the high affinity transporter, has an additional role, acting as a sensor of the available ammonium outside of the cell and transmitting this signal to change cell morphology to the filamentous form. The current study investigated the roles of ploidy (haploid vs. diploid strains), promoter type (native promoter vs. constitutive promoter), gene structure (genomic copy vs. cDNA), and gene location (native location vs. ectopic location) on transcription levels of both ammonium transporters under low ammonium conditions compared to high ammonium conditions.

Ploidy refers to the number of chromosome sets within a cell of an organism. In past studies, it has been found that ploidy can play a role in gene expression, but typically at very low levels (i.e., 2-fold change). Three different strains, haploid, haploid 
solopathogenic and diploid solopathogenic, were used to investigate the role of ploidy in U. maydis. Using qRT-PCR as a measure of gene expression, both the diploid and haploid solopathogenic strains, D132 and SG200, respectively, the expression of the ammonium transporter, ump2, was shown to be significantly affected. This suggests that being primed for pathogenic development was not the factor responsible for ump2 induction, since there was already a functioning $\mathrm{bE} / \mathrm{bW}$ heterodimer within the haploid solopathogenic strain SG200 and substantial induction of ump2 was not observed in that strain. The diploid solopathogenic strain contains complete b1/b2 alleles, which code for the two pieces of the heterodimer (i.e., bE1/bW2) responsible for initiating the pathogenic program. However, in addition, D132 is diploid for the remainder of the genome as well, suggesting effects of the diploid state on ump1 and ump2 expression.

The promoter driving gene expression of ump2 was investigated to see if this had an effect on ump2 gene expression. Expression levels from the native promoter for ump2 were compared to those from a constitutively active promoter, $P_{\text {otef, }}$ in the FB1 background. Results showed that the use of $P_{\text {otef }}$ increased the expression of ump2 dramatically under both high and low ammonium conditions. Surprisingly, use of just one copy of the ump 2 gene via $P_{\text {otef }}$ actually increased ump 2 expression more than having two copies (i.e., one via the native promoter and one via $\left.P_{\text {otef }}\right)($ Fig. $4 a)$. In replete media conditions, the promoter did not seem to have as large of an effect on ump2 expression as it did under low ammonium conditions. When ump2 expression was compared when the gene was driven by $P_{o t e f}$ to that from an overexpression construct containing two copies of ump2 (FB1 $\mathrm{P}_{\text {ump2 } 2}+$ Coding Region), the constitutive promoter had a much larger effect on upregulating ump2 than the construct containing two copies. Under low ammonium 
conditions, the $P_{\text {otef }}$ promoter showed an $8 \log 2$ fold increase in expression under high ammonium conditions while the construct containing two copies of ump2 showed less than a $3 \log 2$ fold change (Fig. 4b).

I also examined the role of gene structure and gene location in affecting expression of the ammonium transporters. Gene structure in this study refers to comparison of expression for the cDNA construct with that of the genomic DNA (gDNA) portion of ump2 used to express ump2. The cDNA copy included only the coding region of ump2 while the gDNA copy included both the exons and the introns. In comparison to the FB1 wild type strain in replete media conditions, both gDNA and cDNA constructs showed increased ump2 expression. Under low ammonium conditions, the strain expressing the cDNA copy increased ump 2 expression slightly less than $4 \log 2$ fold, whereas expression from the gDNA construct actually displayed a slight decrease in ump2 transcription level relative to the same strain under replete conditions. This suggests that there may be some other regulatory components within the introns or the 5 , or 3'UTRs that affect the expression of ump2 by downregulating its expression under low ammonium conditions. Results in the FB1 background were determined under the assumption that the native promoter and gene expression are not effected due to their genomic location. When cloning into U. maydis, the ip locus was used as an ectopic location from the native copy of the ump 2 gene. When using the ip locus, we found that ump2 expression can be restored when replaced with a copy of ump 2 using the native promoter and increases ump 2 expression when ump 2 is driven by the constitutively active promoter. 
The use of the solopathogenic strain SG200 and its mutant derivatives suggests that the presence of at least $u m p 2$ is required for full pathogenicity even in the absence of mating, as these mutants were also severely impaired in disease production. The most parsimonious explanation here is that lacking the high affinity ammonium transporter and therefore a way to sense and obtain ammonium, the mutants are not able to move to the next stage in the host, where nitrogen may initially be limiting. Additionally, while the SG200 mutants complemented with the wild type ump2 cDNA regained the ability to filament on low ammonium (Fig. 5a), they failed to regain either wild type production of aerial hyphae on charcoal or virulence (Fig. $5 \mathrm{~b}$ and 5c, respectively). It was confirmed that the complemented mutants had similar transcription levels of ump2 as wild type (see Fig. 6). Since only cDNA of the coding region was used in these constructs, this suggests additional aspects of ump2 regulation including, e.g., as-yet-unidentified regulatory signals in either the 5'- or 3'-UTR of the ump2 mRNA that were not included in the complementation constructs used here. 


\section{REFERENCES}

Albertin, W., Marullo, P., 2012. Polyplidy in fungi: evolution afterwhole-genome dulication. Proceedings Biology Scientific 279, 2497-2509.

Banuett, F., Herskowitz, I., 1994. Morphological Transitions in the Life Cycle of Ustilago maydis and Their Genetic Control by the a and b Loci. Exp Mycology 18, 247 266.

Brachmann, A., Weinzierl, G., Kamper, J., Kahmann, R., 2001. Identificatin of genes in the $\mathrm{bW} / \mathrm{bE}$ regulatory cascade in Ustilago maydis. Molecular Microbiology 42, 10471063.

Djamei A, K.R., 2016. Ustilago maydis: Dissecting the Molecular Interface between Pathogen and Plant. Plos One 8, 1-4.

Galitski, T., Saldanha, A., Styles, C., Lander, Fink, G., 1999. Ploidy Regulation of Gene Expression. Science 285, 251-254.

Garcia-Pedrajas, M., Baeza-Montanez, L., Gold, S., 2010. Regulation of Ustilago maydis Dimorphism, Sporulation, and Pathogenic Development by a Transcription Factor with a Highly Conserved APSES Domain. The American Phytopathological Society 23, 211222.

Haber, J., 2012. Mating-Type Genes and MAT Switching in Saccharmyces cerevisiae. Genetics 191, 33-64.

Hoshida H., K., M., Kobayashi, T., Yarimizu, T., Akada, R., , 2016. 5'-UTR introns enhance protein expression in the yeast Saccharomyces cercisiae. Applied Microbiology and Biotechology 101, 241-251.

Huang, Y., Xiong, Y., Lin, Z., Feng, X., Jiang, X., Songyang, Z., Huang, J., 2015. Specific Tandem 3'UTR Patterns and Gene Expressin Profiles in Mouse Thy1+ Germline Stem Cells. PLoS ONE 10, 1-17.

Kamper, J., Kahmann, R., Bolker,M., Ma, L., Brefort, T., Saville, B., et al. 2006. Insights from the genome of the biotrophic funga pathogen Ustilago maydis Nature 499, 97-101.

Marini, A., Soussi-Boudekou, S., Vissers, S., Andre, A. 1997. AFamily of Ammonium Transporters in Saccharomyces cerevisae. Molecular and Cellular Biology 17, 42824293.

Paul, J., Barati, M.T., Cooper, M., Perlin, M. 2014. Physical and Genetic Interaction between Ammonium Transporters and the Signaling Protein Rho1 in the Plant Pathogen Ustilago maydis. Eukaryotic Cell 13, 1328-1336. 
Pham, C., Yu, Z., Sandrock, B., Bolker, M., Gold, S., Perlin, M., 2009. Ustilago maydis Rho1 and 14-3-3 homologues participate in pathways controlling cell seperation and cell polarity. Eukaryotic Cell 8, 977-989.

Regenfelder E, S.T., Hartmann A, Lauenstein S, Bölker M, Kahmann R., 1997. G proteins in Ustilago maydis: transmission of multiple signals? EMBO Journal 16, 19341942.

Riddle, N., Jiang,H., Lingling, A., Doerge, R., Birchler, J., 2010. Gene Expression Analysis at the intersection of ploidy and hybridity in maize. Theoretical and Applied Genetics 120, 341-353.

Rutherford, J., G.C., Hughes, T., Cardenas, M., Heitman, J. 2008. A Mep2-dependent Transcriptional Profile Links Permease Fuction to Gene Expression duringPseudohyphal Growth in Saccharomyces cerevisiae. Molecular Biology of the Cell 19, 3028-3039.

Smith, D., Garcia-Pedrajas, M., Gold, S., Perlin, M. 2003. Isolation and characterization from pathogenic fungi of genes encoding ammonium permeases and their roles in dimorphism. Molecular Microbiology 50, 259-275.

Taylor, C., Jost, R., Erskine, W., Nelson, W. 2016. Identifying Stable Reference Genes for qRT-PCR Normalisation in Gene Expression Studies of Narrow-Leafed Lupin (Lupinus angustifolius L.). Plos One

Wahl R, Z.A., Kämper J. , 2010. The Ustilago maydis b mating type locus controls hyphal proliferation and expression of secreted virulence factors in planta. Molecular Microbiology 75, 208-220.

Yun, J, Hwang, I., Wilkins, O., Lau, L., Hyrcza, M., Jayabalasingham, B., Jin, J., McLaurin, J., Tsao, M., Der, S. 2006. Genomic DNA functions as a universal external standard in quantitative real-time PCR. Nucleic Acids Research 34. 


\title{
CURRICULUM VITAE
}

\author{
Kirsten M. Richardson
}

PERSONAL DATA

Title:

M.S. Thesis in Biology Student

Address:

1605 Earl Ave

Louisville, KY 40215

Phone:

(315) 404-0225

Email:

kmrich04@1ouisville.edu

\section{EDUCATION}

2015 B.A. Biology Keuka College Keuka Park, NY

PresentM.S. Thesis Biology University of Louisville Louisville, KY

(Anticipated graduation year: 2017)

\section{HONORS AND AWARDS}

2017 Honor Society, International Member Society

2014 Chi Beta Phi, a national scientific honor fraternity

2011 George H. Ball Scholarship

\section{INTERNSHIPS}

2014 University of Louisville

Louisville, KY

2013 Faxton St. Luke's Healthcare

Utica, NY

2012 Chestnut Commons

Rome, NY

2012 Rome Memorial Hospital

Rome, NY

\section{$\underline{\text { RESEARCH }}$}

2014 University of Louisville

Louisville, K.Y.

Research in Biochemistry and Molecular Biology: "Role of increased miR-29b-1 and miR-29a in endocrine-resistant breast cancer" Dr. Carolyn Klinge, Ph.D., Advisor 


\section{JOB EXPERIENCE}

2016 Eurofins Genomics Laboratory Technician

Kit Packing Team Lead

\section{PUBLICATIONS}

2017 Muluhngwi, P., Krishna A., Vittitow, S., Napier, J., Richardson, K., Ellis, M., Klinge, C. Tamoxifen differentially regulates miR-29b-1 and miR29a expression depending on endocrine-sensitivity in breast cancer cells. Cancer Letters. 388. $230-238$.

2017 Muluhngwi, P., Richardson, K., Napier, J., Rouchka, E., Mott, J., Klinge, C. Estrogen Receptor alpha regulates miR-29b-1/a transcription in CHO-K1 cells and miR-29b-1/a regulate mRNAs important for cell adhesion, cytoskeletal remodeling and development. Journal of Biotechnology. 444. 38 - 47.

\section{GRANTS}

2016 GNAS Research Fund 